Conclusion Massage therapy could be an effective adjuvant to PT in order to reduce the PT duration. However, it does not appear to reduce the requirement for PT.

\section{GP238 SOCIO-DEMOGRAPHIC FACTORS RELATED TO PARENT ENGAGEMENT IN THE NEONATAL INTENSIVE CARE UNIT (NICU)}

${ }^{1,2}$ Laura Whitehill ${ }^{*}$, Joan Smith ${ }^{3},{ }^{4}$ Graham Colditz, ${ }^{5}$ Tiffany Le, ${ }^{5,6}$ Roberta Pineda ${ }^{1}$ University College Dublin School of Medicine, Dublin, Ireland; 'Institute for Public Health, Washington University in St. Louis, St. Louis, USA; ${ }^{3}$ Department of Quality, Safety and Practice Excellence, St. Louis Children's Hospital, St. Louis, USA; ${ }^{4}$ Department of Surgery, Washington University School of Medicine, St. Louis, USA; ${ }^{5}$ Program in Occupational Therapy, Washington University School of Medicine, St. Louis, USA; ${ }^{6}$ Department of Pediatrics, Washington University School of Medicine, St. Louis, USA

\subsection{6/archdischild-2019-epa.297}

Objectives To determine 1) socio-demographic factors related to parent engagement in the NICU, and 2) determine if the Supporting and Enhancing NICU Sensory Experiences (SENSE) program increased parent engagement.

Background Preterm birth results in significant health complications, necessitating infant hospitalization. This alters early sensory experiences which are further impacted by challenges parents face engaging in care $^{1}$. Parent participation in appropriate sensory activities can improve infant developmental outcomes $^{2}$.

Methods Sixty-four infants born $\leq 32$ weeks gestation were randomized to SENSE or standard of care. SENSE included parent education and specific amounts of age-appropriate sensory exposures for parents to conduct each day of hospitalization. Bedside logs were used to record parent engagement in providing sensory exposures to their infants.

Results Being married $(p=0.02)$ and having private insurance $(p=0.003)$, a college degree $(p=0.046)$ and fewer children $(p=0.02)$ related to more parent engagement. The SENSE intervention was related to increased engagement for young mothers $(p<0.001)$ and those living farther from the NICU $(\mathrm{p}<0.001)$ with trends toward more engagement among African-American parents $(p=.07)$.

Conclusion Those with high social risk are less likely to engage in the NICU, but the SENSE program increased engagement among some high-risk groups.

\section{GP239 CASE REPORT: AN IRISH MALE WITH BILATERAL FIBULAR APLASIA TIBIAL CAMPOMELIA AND OLIGOSYNDACTYLY (FATCO) SYNDROME}

${ }^{1}$ Michaela Pentony*, 'Lisa Bradley, ${ }^{1}$ Pamela O'Connor. ' Coombe Women and Children's Hospital, Dublin 8, Ireland; ' Our Lady's Children's Hospital Crumlin, Dublin, Ireland

\subsection{6/archdischild-2019-epa.298}

Introduction FATCO (Fibular Aplasia, Tibial Campomelia and Oligosyndactyly) syndrome is a rare descriptive diagnosis first defined by Courtens et al. in 2005, who recognised a comparable pattern of malformations with his own case and 4 others described in the literature. ${ }^{1}$ Aetiology remains unknown, however defects involved in $\mathrm{SHH}$ (Sonic hedgehog) gene expression have been proposed. ${ }^{2}$

Case description We report on a term male infant born with severe malformations. On examination, there was absence of the left radius and ulna, bilateral anterior angulation of lower limbs with skin dimpling overlying. Both ankle joints were dysplastic and there was oligosyndactly of both feet. Right upper limb was normal. X-rays of the limbs revealed dysplastic tibiae, absence of both fibulae, a right foot containing 3 ossified metatarsals with 2 formed digits, and a left foot with a single ossified metatarsal and two soft tissue digits with small bony elements. The infant had no other associated anomalies, and is developmentally appropriate at 1 year. Management included Symes amputation, prosthetics and following genetic referral, FATCO syndrome was suggested as the best fitting diagnosis. Whole genome sequencing of infants blood is currently being performed.

Discussion This is an important case to report as there are very few descriptions in the literature,${ }^{1-5}$ In keeping with the majority of reports, this case appears to be sporadic and development is normal. ${ }^{1,3,4}$ Our case is male, keeping with preponderance. ${ }^{1,3-5}$ Treatment aims at optimising functionality of limbs and stabilisations of joints. ${ }^{1-5}$

\section{REFERENCES}

1. Courtens W, Jespers A, Harrewijn I, Puylaert D, VAnhoenacker F. Fibular aplasia, tibial campomelia, and oligosyndactyly in a male newborn infant: a case report and review of the literature. Am J Med Genet $A$ 2005;134(3):321-5.

2. Bieganski T, Jamsheer A, Sowinska A, Baranska D, Niedzielski K, Kozlowski K, Czarny-Ratajczak M. 2012. Three new patients with FATCO: Fibular agenesis with ectrodactyly. Am J Med Genet Part A 158A:1542-1550.

3. Petricevic J, Curic A, Karaman I, Forempoher G, Definis-Gojanovic M (2017) First Case of Bilateral Fibular Aplasia, Tibial Campomelia and Oli- godactyly Syndrome (FATCO Syndrome). J Clin Stud Med Case Rep 4: 046.

4. Karaman A, Kahveci H. A male newborn infant with Fatco syndrome (fibular aplasia, tibial campomelia and oligodactyly): a case report. Genet Couns 2010;21 (3):285-8.

5. Goyal, Navendu, et al. 'FATCO Syndrome Variant - Fibular Hypoplasia, Tibial Campomelia and Oligosyndactyly - A Case Report.' Journal of Clinical and Diagnostic Research: JCDR 8.9 (2014): LD01-LD02. PMC. Web.

\section{GP240 VITAMIN D SUFFICIENCY AND CYTOKINES LEVEL IN NEWBORNS BORN BY MOTHERS WITH OBESITY}

${ }^{1}$ Victoria Kuryaninova, ${ }^{1}$ Natalya Verisokina, ${ }^{2}$ Irina Zakharova*, ${ }^{1}$ Leonid Klimov, ${ }^{1,3}$ Tatyana Zeleznyakova, 'Svetlana Dolbnya, 'Dmitriy Bobryshev, ${ }^{1}$ Meline Petrosyan. ${ }^{1}$ Stavropol State Medical University, Stavropol, Russian Federation; ${ }^{2}$ Russian Medical Continuing Postgraduate Academy, Moscow, Russian Federation; ${ }^{3}$ Stavropol State Clical Perinatal Centre, Stavropol, Russian Federation

10.1136/archdischild-2019-epa.299

Introduction Presence of obesity in mothers negatively affects antenatal life and decreases the sufficiency of Vitamin D in newborns. Recently, cytokines role in the regulation of the condition of the immune system during the development and in the course of infectious diseases was actively studied.

Work objective Vitamin D and cytokines level (interleukin-1 $\beta$ (IL-1 $\beta$ ), interleukin-6 (IL-6)) analysis in newborns, born by mothers with obesity.

Methods during the first 3 days of life a laboratory study of 78 newborns was conducted: $54(69.2 \%)$ were born by mothers with obesity, control group (CG) - 24 (30.8\%) children.

Results Mean gestational age of children, born by mothers with obesity - 37.7 \pm 0.3 weeks, CG - 39.3 \pm 0.2 weeks $(\mathrm{p}<0.001)$. Body weight of newborns - 3345.0 [2600.03980.0] grams and 3350.0 [3060.0-3785.0] grams respectively. In children of mothers with obesity the level of Vitamin D was 7.7 [4.0-14.5] $\mathrm{ng} / \mathrm{ml}$, which is 1.3 times 